\title{
The grounding zone of the Ross Ice Shelf, West Antarctica, from ice-penetrating radar
}

\author{
Joseph A. MacGREGOR, ${ }^{1}$ Sridhar ANANDAKRISHNAN, ${ }^{2}$ Ginny A. CATANIA, ${ }^{1,3}$ \\ Dale P. WINEBRENNER ${ }^{4,5}$ \\ ${ }^{1}$ Institute for Geophysics, University of Texas at Austin, Austin, Texas 78758-4445, USA \\ E-mail: joemac@ig.utexas.edu \\ ${ }^{2}$ Department of Geosciences, The Pennsylvania State University, 442 Deike Building, University Park, \\ Pennsy/vania 16802-2711, USA \\ ${ }^{3}$ Department of Geology, University of Texas at Austin, Austin, Texas 78713-7909, USA \\ ${ }^{4}$ Polar Science Center, Applied Physics Laboratory, University of Washington, 1013 NE 40th Street, Seattle, \\ Washington 98105-6698, USA \\ ${ }^{5}$ Department of Earth and Space Sciences, University of Washington, Seattle, Washington 98195-1310, USA
}

\begin{abstract}
As ice streams flow into the Ross Ice Shelf, West Antarctica, their bed coupling transitions from weak to transient to zero as the ice goes afloat. Here we explore the nature of the bed across these crucial grounding zones using ice-penetrating radar. We collected several ground-based $2 \mathrm{MHz}$ radar transects across the grounding zones of Whillans and Kamb Ice Streams and inferred bed-reflectivity changes from in situ measurements of depth-averaged dielectric attenuation, made possible by the observation of both primary and multiple bed echoes. We find no significant change in the bed reflectivity across either grounding zone. Combined with reflectivity modeling, this observation suggests that a persistent layer of subglacial water $(>\sim 0.2 \mathrm{~m})$ is widespread several kilometers upstream of the grounding zone. Our results are consistent with previous inferences of gradual grounding zones across this sector of the Ross Ice Shelf from airborne radar and satellite altimetry. Separately, the only clear bed-reflectivity change that we observed occurs $\sim \mathbf{4 0} \mathbf{~ k m}$ downstream of the Kamb Ice Stream grounding zone, which we attribute to the onset of marine ice accretion onto the base of the ice shelf. This onset is much nearer to the grounding zone than previously predicted.
\end{abstract}

\section{INTRODUCTION}

Grounding zones are the regions of dynamic transition between grounded ice streams and floating ice shelves; across these zones, the ice stream progressively decouples from its bed. It transitions from being fully grounded at the upstream end of the grounding zone, to ephemerally grounded within it, to fully afloat and in hydrostatic balance with the ocean at its downstream end. Brunt and others (2010) used repeat-track satellite-altimetry data to delineate the grounding zone of the Ross Ice Shelf, West Antarctica (Fig. 1), which can be up to $\sim 10 \mathrm{~km}$ wide. Where the ice is already weakly grounded (e.g. the ice plain downstream of Whillans Ice Stream), they found significant differences in the position of the grounding zone that they inferred compared to the grounding line inferred using other methods (e.g. the surface-slope break of a digital elevation model; Horgan and Anandakrishnan, 2006). Characterizing these regions may prove critical to understanding the interaction between grounded ice and the ocean (Winberry and others, 2009; Brunt and others, 2010). As a result, reducing the grounding zone to a grounding line, as is typical for ice-sheet models, may oversimplify the already complex ice dynamics there (e.g. Schoof, 2007).

Ice-penetrating radar surveys can potentially detect spatial variations in the basal properties of ice masses and help elucidate the nature of the grounding zone, particularly by detecting the presence of subglacial water. Several studies have described the Ross ice streams' regional distribution of subglacial water using radar (Shabtaie and others, 1987; Bentley and others, 1998; Catania and others, 2003; Peters and others, 2005; Jacobel and others, 2009). These studies have found evidence that the bed is not uniformly wet, and that the distribution of water is often consistent with predicted minima in the subglacial hydraulic head, where water should collect. The grounding lines of several Antarctic ice shelves have been surveyed using radar (Jacobel and others, 1994; Uratsuka and others, 1996; Bentley and others, 1998; Corr and others, 2001; Catania and others, 2010). However, these studies did not typically consider in detail the nature of the bed across the grounding zone, as revealed by radar. Some of these surveys (e.g. Bentley and others, 1998) crossed the Ross Ice Shelf grounding zone but did not consistently detect a clear transition in bed reflectivity there. This observation is somewhat surprising, as the bed presumably transitions from being grounded on till to floating on sea water and should produce a detectable reflectivity contrast.

Here we seek to better understand the spatial variations in basal conditions across the grounding zone of the Ross Ice Shelf using several ground-based radar transects across the grounding zones of Whillans and Kamb Ice Streams (Fig. 1). We use separate radar-inferred attenuation-rate estimates for each radar transect crossing the grounding zone, rather than a single regional value, in order to better resolve possible bed-reflectivity changes there. We report on bed reflectivities across these grounding zones and consider the implications for the nature of the ice/bed/ocean interface within and near this region.

\section{RADAR DATA}

We collected 11 ground-based radar transects that crossed the grounding line of the Ross Ice Shelf, as demarcated by 


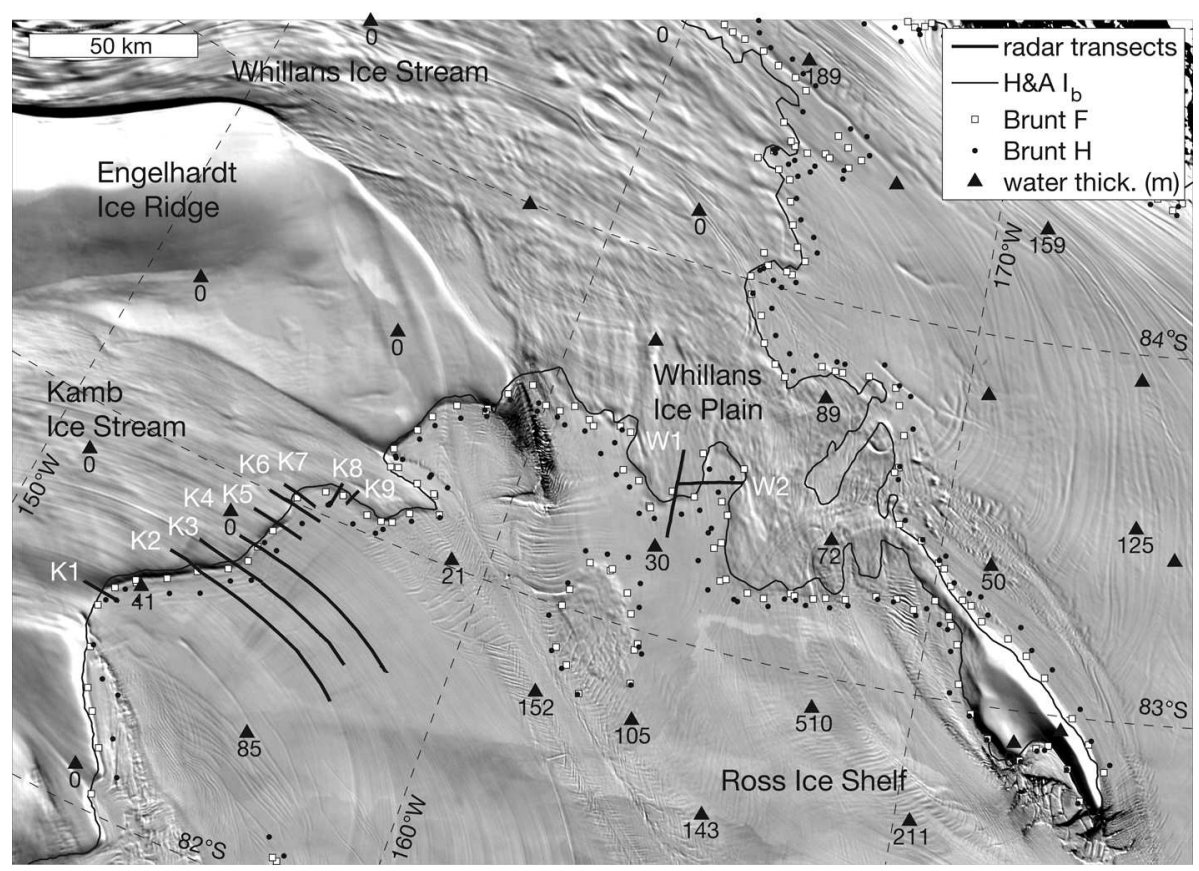

Fig. 1. (a) Moderate Resolution Imaging Spectroradiometer (MODIS) Mosaic of Antarctica image (125 m resolution) of grounding zone of the Ross Ice Shelf (Scambos and others, 2007) showing the ground-based radar transects used in this study. The thin black line between the Ross Ice Shelf and the ice streams/ridges is the grounding line determined by Horgan and Anandakrishnan (2006) ('H\&A I $\mathrm{b}_{\mathrm{b}}$ ). The white boxes and black dots represent the landward limit of ice flexure $\left({ }^{\prime} \mathrm{F}^{\prime}\right)$ and the point at which the ice shelf is in stable hydrostatic equilibrium with the ocean (' $\mathrm{H}^{\prime}$ ), both picked by Brunt and others (2010). Black triangles represent Ross Ice Shelf Geophysical and Glaciological Survey (RIGGS) sites. Water-column thicknesses are from seismic data (Robertson and Bentley, 1990). Triangles with no number indicate RIGGS sites where seismic data were either unreported or not collected.

Horgan and Anandakrishnan (2006) (Fig. 1). Brunt and others (2010) picked the up- and downstream limits of ice flexure across the grounding zone using Ice, Cloud and land Elevation Satellite (ICESat) tracks, and we linearly interpolated their discontinuous grounding-zone picks onto the positions of our transects (e.g. Fig. 2). The grounding zone defined by Brunt and others (2010) was completely crossed by 9 of our 11 transects. These transects were originally collected for a study of the ice-flow history and possible grounding-line retreat in this region.

We used a snowmobile-towed ice-penetrating radar system similar to that described by Catania and others (2008) and summarized here. Two resistively loaded $2 \mathrm{MHz}$ dipole antennas were dragged on the snow surface at a separation of $\sim 100 \mathrm{~m}$, while an impulse generator induced $2 \mathrm{kV}$ pulses into the transmitting antenna. A digital oscilloscope recorded the subsequent voltages induced in the receiving antenna, and a survey- or navigation-grade GPS provided positioning. The data were demeaned and filtered using a $0.25-10 \mathrm{MHz}$ bandpass. Bed-echo intensities are calculated following Gades and others (2000); the amplitudes of the reflected wave are squared and summed across a travel-time period equal to twice that of the period between the maximum (positive) and minimum (negative) reflection amplitudes, i.e. the first cycle of the reflected radio wave. We then averaged these values across the mean radius of the first Fresnel zone for the primary bed echo in all transects used in this study $(160 \mathrm{~m})$. We chose not to migrate these radar data because the characteristics of the ice/bed interface in our study area suggest that migration is not necessary to effectively analyze bed-echo intensities there. The horizontal slope of primary bed echo is generally low $\left(<0.02 \mu \mathrm{sm}^{-1}\right)$ and the echoes themselves are generally highly coherent; combined, these observations suggest that migration will have a limited effect upon essentially specular bed reflections from nadir or close to nadir.

All of our radar transects recorded both the primary bed echo and the first multiple of the bed echo. The latter echo reflected from the ice bottom, then the firn/air interface, then ice bottom again, and finally was recorded by our radar system at the surface. Multiple echoes are rarely observed in ice-penetrating radar surveys because the total power loss of the radio signal transmitted into the ice that occurs along multi-kilometer ray paths is large (often $\gg 100 \mathrm{~dB}$ ) compared to a typical radar's system performance (90 to $>200 \mathrm{~dB}$; table 1 of Gogineni and others, 1998; C. Allen, http://www.earthzine.org/2008/09/26/a-briefhistory-of-radio-echo-sounding-of-ice/). However, multiple bed echoes have occasionally been recorded in surveys of relatively thin $(<1 \mathrm{~km})$ floating ice, such as ice shelves (Shabtaie and Bentley, 1982; Uratsuka and others, 1996), icebergs (Peters and others, 2007) and landfast sea ice (e.g. Stevens and others, 2009). Below we describe in detail two characteristic radargrams from these surveys (Figs 2 and 3), although we analyzed bed reflectivity across all transects (Figs 4 and 5).

$\mathrm{W} 1$ is a $22 \mathrm{~km}$ long transect that crosses the lightly grounded Whillans Ice Plain (Joughin and others, 2004; Winberry and others, 2009) onto the Ross Ice Shelf (Fig. 2). This transect is oriented $\sim 45^{\circ}$ to the direction of ice flow (Anandakrishnan and others, 2007). The sub-ice reflections that are not multiple bed reflections include a subglacial till wedge previously reported by Anandakrishnan and others (2007) and several off-nadir reflections. Between km 6.5 and $\mathrm{km} 10$, the radar system's receiver gain was manually lowered by $5 \mathrm{~dB}$ (labeled in Fig. 2a). 


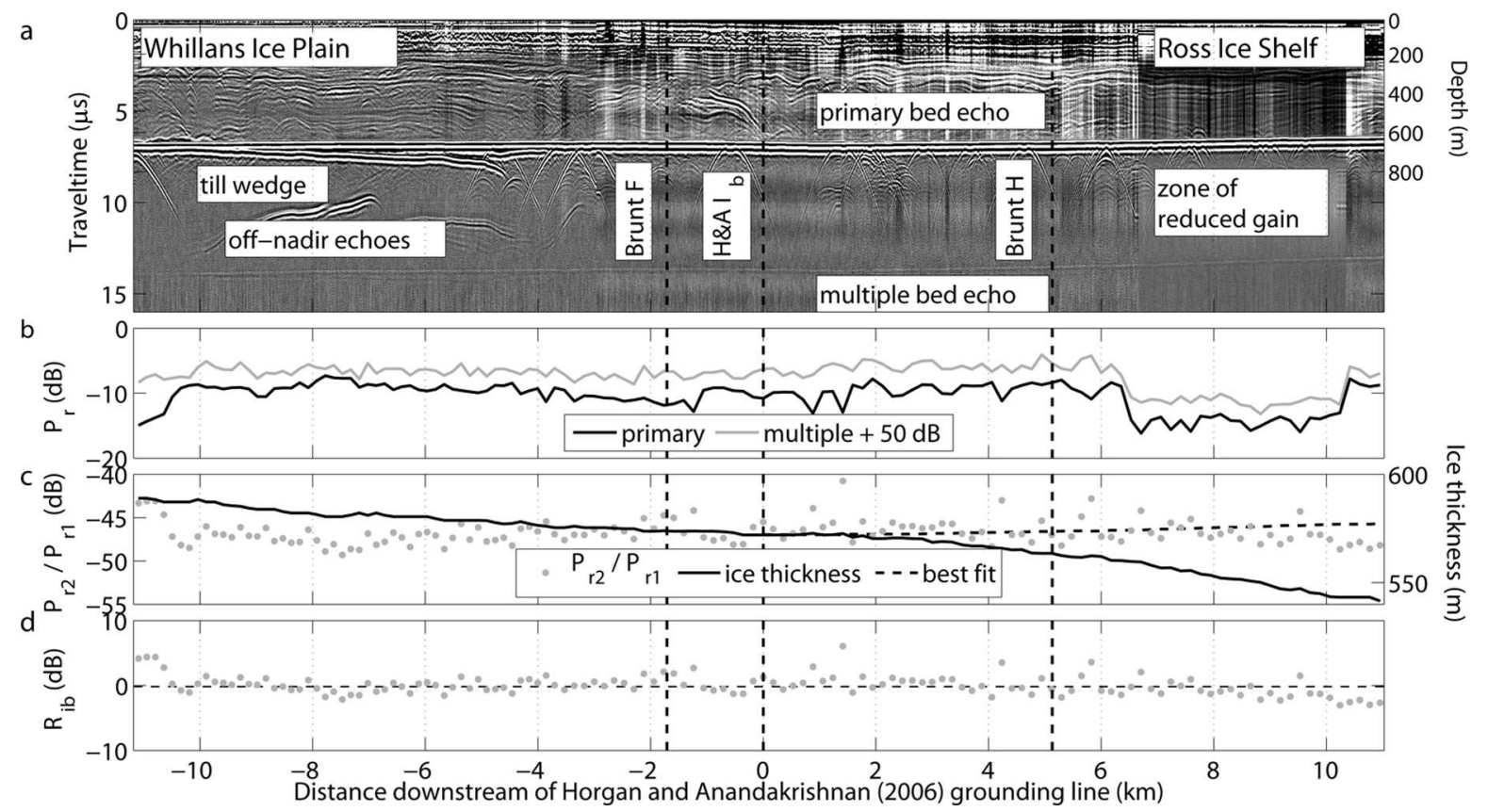

Fig. 2. (a) W1 radar transect, corrected for surface elevation. Linearly interpolated grounding-line and grounding-zone picks from Figure 1 are shown as vertical dashed lines. (b) Echo intensities $P_{\mathrm{r} 1}$ and $P_{\mathrm{r} 2}$, averaged over the mean radius of the first Fresnel zone for all transects $(160 \mathrm{~m})$. The absolute reference value for the decibel scale is arbitrary, and $P_{\mathrm{r} 2}$ has been increased by $50 \mathrm{~dB}$ for simpler comparison with $P_{\mathrm{r} 1}$. (c) Echo-intensity ratio $P_{\mathrm{r} 2} / P_{\mathrm{r} 1}$, ice thickness and the constrained least-squares fit to Equation (4) using the portion of the transect downstream of the grounding line (dashed line). (d) Ice-bottom reflectivity $R_{\mathrm{ib}}$ inferred from Equation (3) and the radar-derived value of $N_{\mathrm{a}}$. The horizontal dashed line is the reflectivity of a specular ice/sea-water interface $\left(R_{\mathrm{ib}}=-0.16 \mathrm{~dB}\right)$.

$\mathrm{K} 4$ is a $60 \mathrm{~km}$ long flow-parallel transect that also recorded a complex sequence of echoes both before and after the primary bed echo (Fig. 3), but here we focus on the primary and multiple bed echoes. $\mathrm{K} 4$ is a concatenation of three profiles collected on the same day, and there are three low-frequency 'waves' visible in the data that disappear within $5 \mathrm{~km}$ downstream of each concatenation. They are associated with the radar-system warm-up after the beginning of recording and are not correlated with changes in the echo intensity of the primary bed echo or its multiple. Compared to W1, K4 was collected using a more repeatable impulse generator, is flow-parallel and crosses a grounding zone that is more clearly defined by basal crevassing and a local decrease in ice thickness. The improved impulse
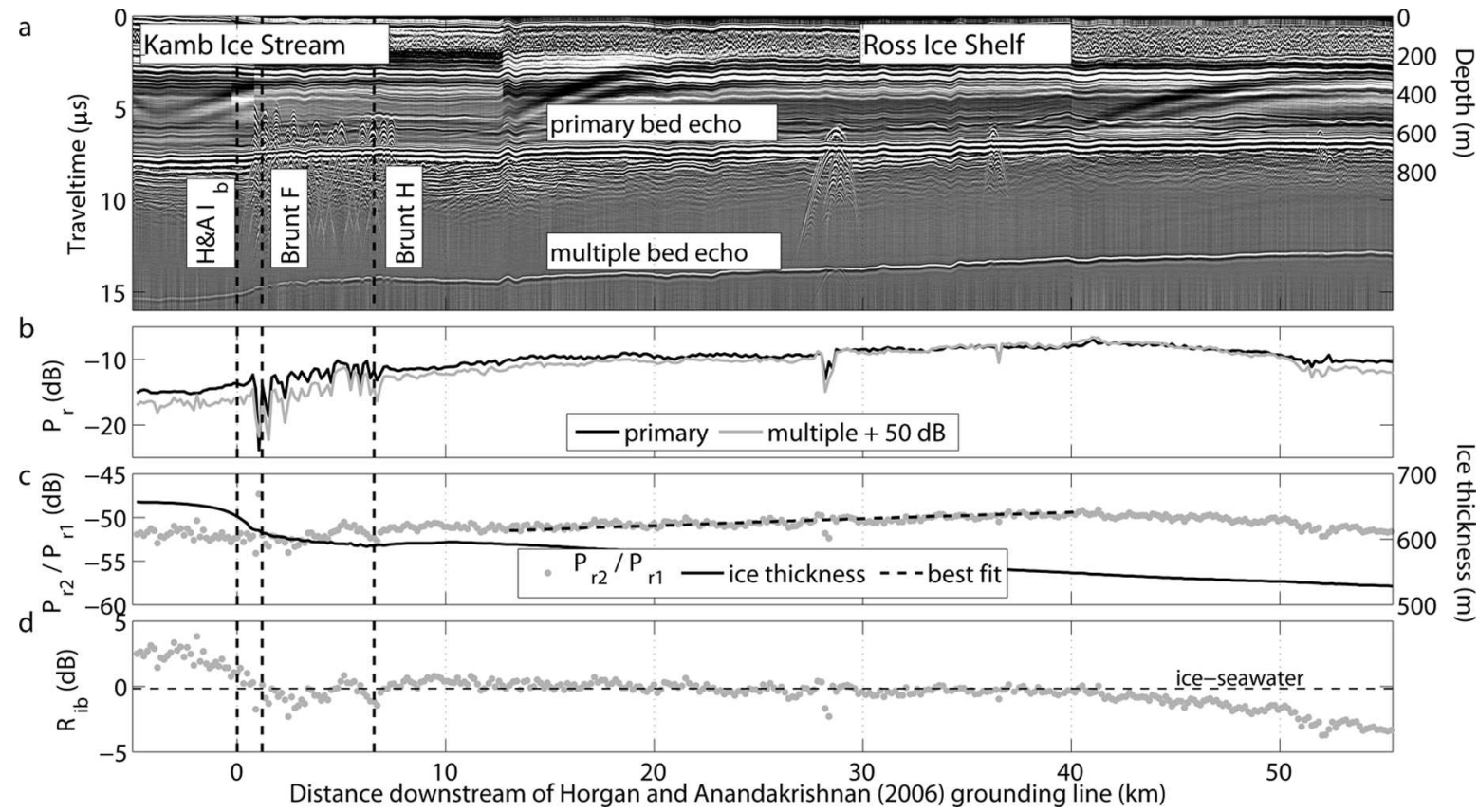

Fig. 3. Same format as Figure 2. (a) K4 radar transect. Note that the greyscale range is four times narrower than for Figure 2a. (b) $P_{\mathrm{r} 1}$ and $P_{\mathrm{r} 2}$. (c) $P_{\mathrm{r} 2} / P_{\mathrm{r} 1}$, ice thickness and the constrained least-squares fit to Equation (4) between $\mathrm{km} 13$ and $\mathrm{km} 40$. (d) $R_{\mathrm{ib}}$. 


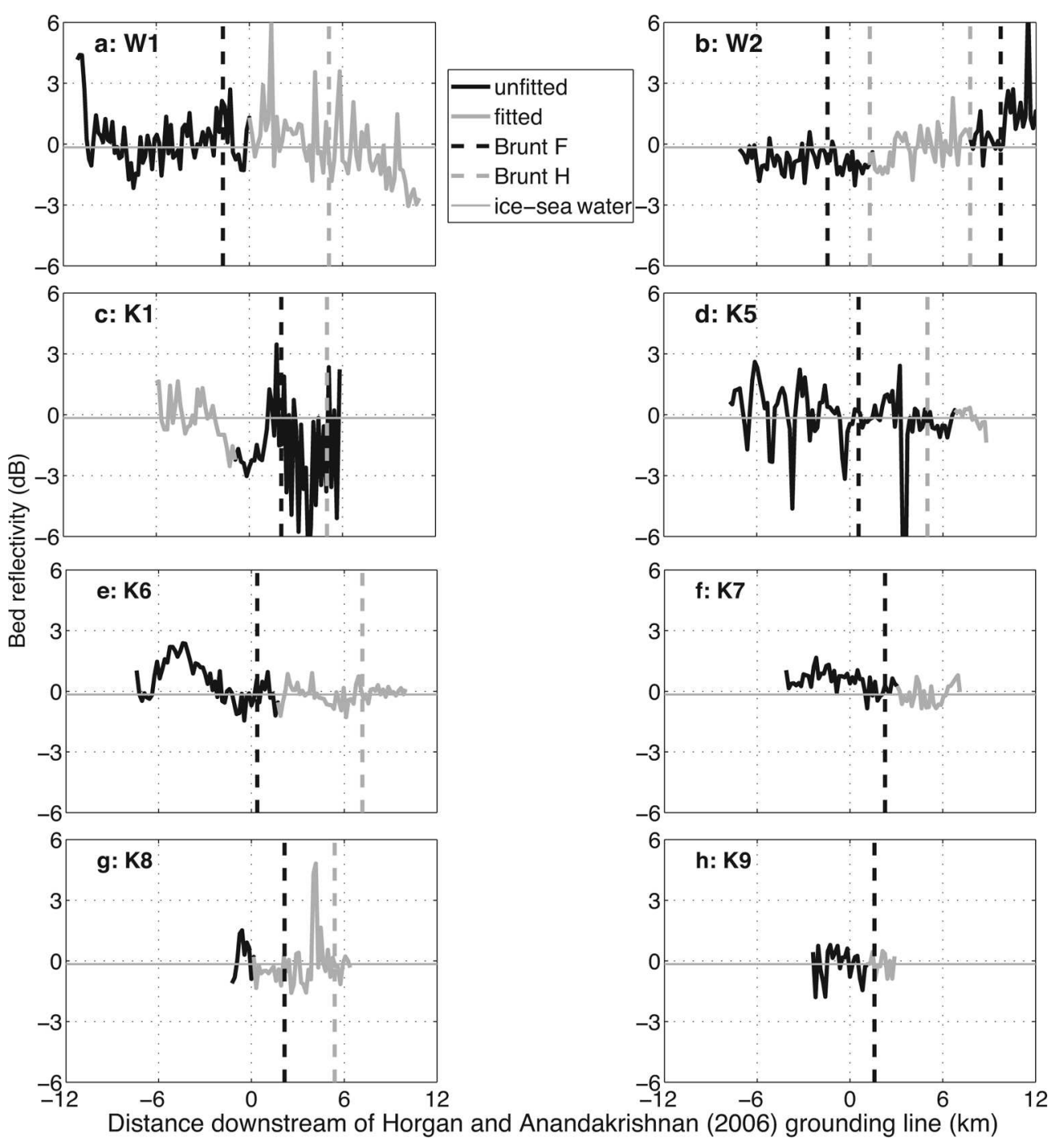

Fig. 4. Bed reflectivity for all transects less than $25 \mathrm{~km}$ long, inferred using each transect's depth-averaged attenuation rate (Table 1). The 'fitted' portion of the transect is that over which the depth-averaged attenuation rate is calculated by assuming that the bed reflectivity was equal to that of a specular ice/sea-water interface $(-0.16 \mathrm{~dB})$. The 'unfitted' portion is the remainder.

generator was used for all transects except W1, making W1 the noisiest of our 11 transects.

\section{ATTENUATION RATE FROM MULTIPLE ECHOES}

Prior to any bed-reflectivity analysis, observed bed-echo intensities must be corrected for both system and englacial losses. The largest uncertainty in these corrections is often associated with the englacial dielectric attenuation (e.g. Bentley and others, 1998), which is generally poorly known due to the challenge of measuring it, along with its dependence on spatially varying englacial temperature and impurity concentrations. Previous ground-based estimates of attenuation rates have used either common-midpoint geometries (Winebrenner and others, 2003), common-offset data with the assumption that the basal reflectivity was uniform across the survey area (Gades and others, 2000; Catania and others, 2003; Winebrenner and others, 2003; Jacobel and others, 2009), or profiles of returned power vs depth (Matsuoka and others, 2010). Below we present a new method for inferring the depth-averaged radar-attenuation rate from multiple bed echoes and apply it to our groundingzone transects.

\subsection{Method}

Multiple echoes have previously been used in seismic reflection studies of ice sheets to estimate englacial acoustic attenuation and basal reflectivity (Roethlisberger, 1972; Smith, 1997; Peters and others, 2008). Here we adopt a method originally developed for acoustic waves (e.g. Roethlisberger, 1972) and apply it to radar data. We note that our methodology does not include the common coefficient error described by Holland and Anandakrishnan (2009). The echo intensity $P_{\mathrm{r} 1}$ of the primary bed reflection is given by the radar equation (e.g. Bogorodsky and others, 1985):

$$
P_{\mathrm{r} 1}=\frac{P_{\mathrm{t}} G^{2}}{4 \pi(2 H)^{2}} \exp \left(\frac{-2 H}{L_{\mathrm{a}}}\right) R_{\mathrm{ib}}
$$

where $P_{\mathrm{t}}$ is the transmitted power, $G$ is the effective antenna gain (identical for both transmitting and receiving antennas), $H$ is the ice thickness, $L_{a}$ is the depth-averaged attenuation length and $R_{\mathrm{ib}}$ is the (power) reflectivity of the ice bottom. We ignore loss due to birefringence and volume scattering, because these effects are small compared to the other terms in Equation (1) at $2 \mathrm{MHz}$ (equivalent to a wavelength in ice 


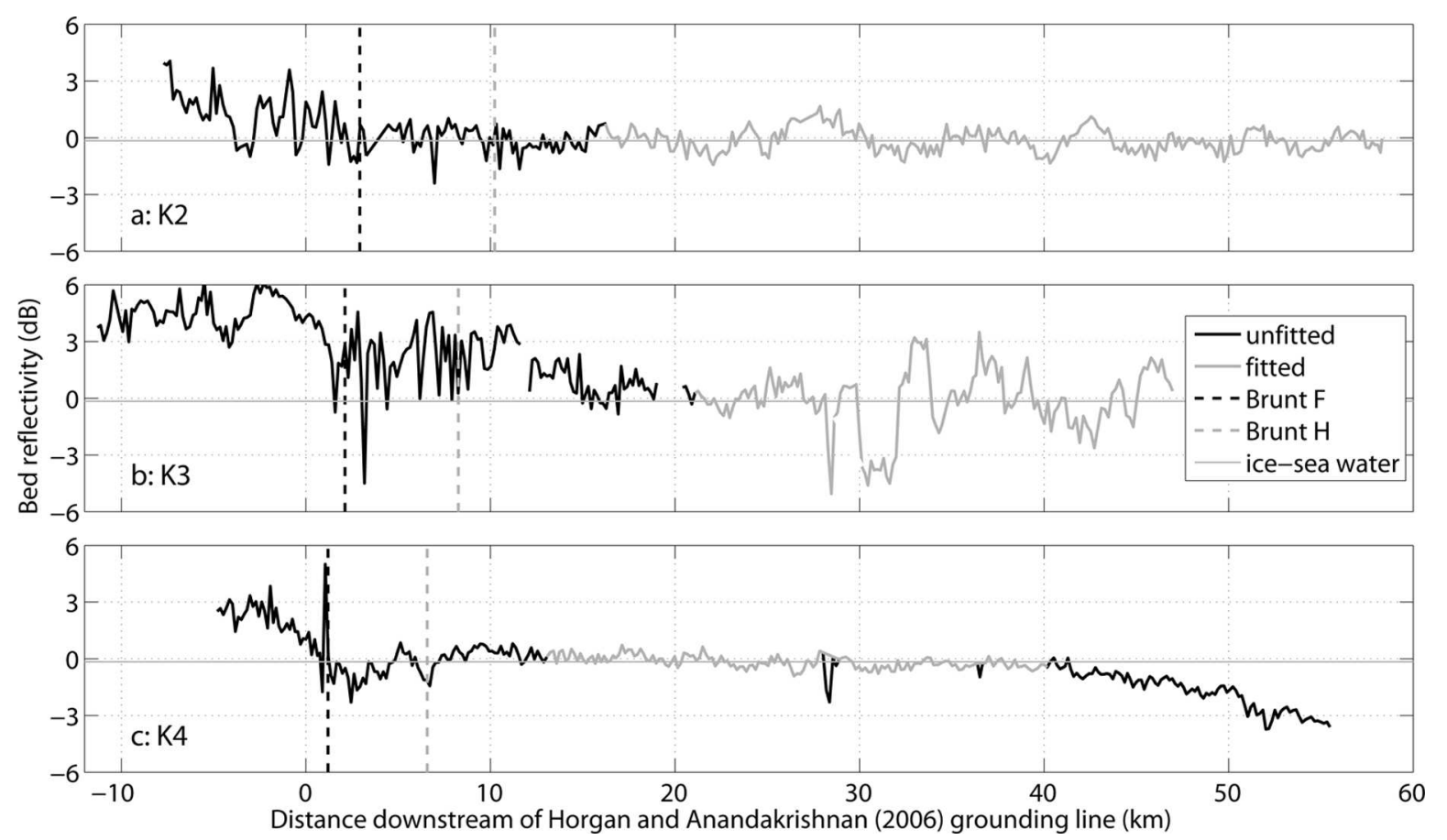

Fig. 5. Bed reflectivity along longer transects K2, K3 and K4. Same format as Figure 4.

of $\sim 85 \mathrm{~m}$; MacGregor and others, 2007). For a typical radar survey, most quantities in Equation (1) except $P_{\mathrm{r} 1}$ and $H$ are poorly known, so $L_{\mathrm{a}}$ cannot be reliably estimated. However, if a multiple bed echo is also recorded, then many of the quantities in Equation (1) can be eliminated. The echo intensity $P_{\mathrm{r} 2}$ of the first multiple bed reflection is

$$
P_{\mathrm{r} 2}=\frac{P_{\mathrm{t}} G^{2}}{4 \pi(4 H)^{2}} \exp \left(\frac{-4 H}{L_{\mathrm{a}}}\right) R_{\mathrm{ib}}{ }^{2} R_{\mathrm{fa}},
$$

where $R_{\mathrm{fa}}$ is the (power) reflectivity of the firn/air interface. Equation (2) accounts for the additional attenuation and geometric spreading due to the extra round-trip that the radio wave travels, the reflection at the firn/air interface, and the second reflection at the bed. The echo-intensity ratio of $P_{\mathrm{r} 2}$ to $P_{\mathrm{r} 1}$ is:

$$
\frac{P_{\mathrm{r} 2}}{P_{\mathrm{r} 1}}=\frac{1}{4} \exp \left(\frac{-2 H}{L_{\mathrm{a}}}\right) R_{\mathrm{ib}} R_{\mathrm{fa}} .
$$

Using Equation (3), we can infer $L_{\mathrm{a}}$ from observations of $P_{\mathrm{r} 2} / P_{\mathrm{r} 1}$ and $H$, and estimates of $R_{\mathrm{ib}}$ and $R_{\mathrm{fa}}$ discussed below. To determine the best-fit $L_{\mathrm{a}}$ value, we calculate a linear leastsquares fit to Equation (3) in log space that is constrained to pass through the origin:

$$
\log _{e}\left(\frac{4}{R_{\mathrm{ib}} R_{\mathrm{fa}}} \frac{P_{\mathrm{r} 2}}{P_{\mathrm{r} 1}}\right)=-\frac{2}{L_{\mathrm{a}}} H .
$$

Finally, we convert $L_{\mathrm{a}}(\mathrm{m})$ to a depth-averaged attenuation rate $N_{\mathrm{a}}\left(\mathrm{dB} \mathrm{km}^{-1}\right)$ as (Winebrenner and others, 2003)

$$
N_{\mathrm{a}}=\frac{4343}{L_{\mathrm{a}}} \text {. }
$$

Although each radar trace could, in principle, be used to obtain an independent estimate of $N_{a}$, the observed values of $P_{\mathrm{r} 1}$ and $P_{\mathrm{r} 2}$ are noisy (e.g. Fig. 2b), so we prefer to use a best-fit value using data from regions where $N_{\mathrm{a}}, R_{\mathrm{ib}}$ and $R_{\mathrm{fa}}$ are argued to be uniform. In this sense, the multiple-echo method of estimating attenuation is restricted in the same way as the common-offset method of Winebrenner and others (2003), i.e. both methods require radar data from a range of ice thicknesses over which $N_{\mathrm{a}}, R_{\mathrm{ib}}$ and $R_{\mathrm{fa}}$ are assumed to be uniform.

We use a constrained linear least-squares fit in log space, rather than an unconstrained fit, because the ice-thickness range over which we fit these data (typically $<50 \mathrm{~m}$ and sometimes $<5 \mathrm{~m}$; Table 1 ) is small relative to the mean ice thickness $(590 \mathrm{~m})$ and the expected attenuation lengths ( $\sim 150-250 \mathrm{~m})$. In log space, the $y$-intercept of Equation (3) is $R_{\mathrm{ib}} R_{\mathrm{fa}} / 4$, therefore these data could be used to constrain the product of the interface reflectivities, $R_{\mathrm{ib}} R_{\mathrm{fa}}$. However, an unconstrained fit using a relatively small ice-thickness range cannot adequately determine the value of $R_{\mathrm{ib}} R_{\mathrm{fa}} / 4$ at zero ice thickness. Separate calculations using an unconstrained fit produce widely varying attenuation-rate estimates compared to most previously reported radar-derived values for this region (Jacobel and others, 2009).

\subsection{Firn/air reflectivity}

The firn/air reflectivity, $R_{\mathrm{fa}}$ depends on both the abrupt discontinuity in complex permittivity at the firn/air interface and its depth profile in the near-surface firn. We assume $R_{\mathrm{fa}}$ only depends on the real part of the complex permittivity (hereafter permittivity) and that the firn properties that affect permittivity (primarily density) do not vary significantly across our study region. For all transects, we use the same $R_{\mathrm{fa}}$ value, whose calculation is described below.

The nearest measured depth-density profile to our transects is from the J-9 ice core on the Ross Ice Shelf (Langway, 1975). The depth-density profile was also measured at Siple Dome, but we consider the J-9 profile to be more likely to be representative of the density profile at the ice-stream grounding zones, which are at lower surface elevations than Siple Dome. We approximated the J-9 depthdensity profile as a second-order polynomial and converted it into a permittivity profile following Looyenga (1965), assuming the permittivity of ice is 3.2. We then used this 
Table 1. Radar-derived depth-averaged attenuation rates for all transects in this study

\begin{tabular}{|c|c|c|c|c|c|}
\hline Region & Transect & $\begin{array}{l}\text { Total length } \\
\mathrm{km}\end{array}$ & $\begin{array}{l}\text { Length of fit } \\
\qquad \mathrm{km}\end{array}$ & $\begin{array}{l}\text { Ice-thickness range for fit } \\
\text { m }\end{array}$ & $\begin{array}{l}\text { Depth-averaged attenuation rate* } \\
\qquad \mathrm{dB} \mathrm{km}{ }^{-1}\end{array}$ \\
\hline \multirow[t]{2}{*}{ Whillans Ice Plain } & W1 & 22.2 & 11.0 & 35.5 & $20.8 \pm 9.9$ \\
\hline & W2 & 19.6 & 6.4 & 28.8 & $22.9 \pm 7.4$ \\
\hline Northern KIS GZ & K1 & 9.2 & 9.2 & 2.5 & $23.0 \pm 5.2^{*}$ \\
\hline Central KIS GZ & K2 & 66.1 & 42.1 & 44.9 & $26.8 \pm 1.3$ \\
\hline \multirow[t]{2}{*}{ and Ross Ice Shelf } & K3 & 58.4 & 25.9 & 31.3 & $27.1 \pm 7.5$ \\
\hline & K4 & 60.4 & 27.0 & 44.0 & $23.9 \pm 0.0$ \\
\hline \multirow[t]{5}{*}{ Southern KIS GZ } & K5 & 11.4 & 4.1 & 3.4 & $22.6 \pm 36.2$ \\
\hline & K6 & 9.5 & 9.5 & 13.5 & $27.1 \pm 26.5$ \\
\hline & K7 & 12.0 & 5.2 & 52.4 & $27.1 \pm 89.9$ \\
\hline & K8 & 17.5 & 8.2 & 4.2 & $27.1 \pm 17.3$ \\
\hline & K9 & 16.6 & 2.0 & 5.6 & $28.1 \pm 56.2$ \\
\hline
\end{tabular}

\footnotetext{
*Uncertainty is the standard error of the least-squares fit to Equation (4).

†Kamb Ice Stream grounding zone.
}

For this transect, we only fitted to data upstream of the grounding line.

profile in an integration of the Riccati equation for reflectivity (Sylvester and others, 1996). We account for the abrupt firn/ air interface by adapting the acoustic calculation of Winebrenner (1991) to the case of electromagnetic waves. From these methods, we obtain $R_{\mathrm{fa}}=-17 \pm 1.5 \mathrm{~dB}$, which primarily depends (to within $<1 \mathrm{~dB}$ ) on the abrupt firn/air interface, rather than the permittivity profile. The uncertainty in $R_{\mathrm{fa}}$ is based on the residuals of the polynomial fit to the J-9 density profile, which are propagated through the calculation of $R_{\mathrm{fa}}$. This modeled value of $R_{\mathrm{fa}}$ and its uncertainty are close to (within $1 \mathrm{~dB}$ of) the mean and standard deviation of $R_{\mathrm{fa}}$ that Peters and others (2005) inferred from airborne radar data collected over Kamb Ice Stream.

\subsection{Ice/sea-water reflectivity}

For the portions of the transects where we calculate the bestfit attenuation rate, we assume that the ice bottom is a smooth ice/sea-water interface, identical to the approach taken by airborne radar surveys to estimate attenuation over ice shelves (Bentley and others, 1998; Peters and others, 2005). We assume that the reflection is specular at $2 \mathrm{MHz}$ and calculate its reflectivity $\left(R_{\mathrm{ib}}=-0.16 \mathrm{~dB}\right)$ using the Fresnel equations and the complex relative permittivities of ice $\left(\varepsilon_{\text {ice }}=3.2-0.63 i\right)$ at the bed; MacGregor and others, $2007)$ and sea water $\left(\varepsilon_{\text {sea-water }}=79.7-\left(2.4 \times 10^{4}\right) i\right)$ at $2 \mathrm{MHz}$. The values for sea water are from measurements by Ellison and others (1998) at a frequency of $3 \mathrm{GHz}$ and temperature of $-2^{\circ} \mathrm{C}$.

\subsection{Application to grounding-zone transects}

Because of the range in transect extents across the grounding zone, and because of features unique to some transects, we make several minor adjustments to the method described above. For each transect, we calculate the depth-averaged attenuation rate using the portion of the transect that is downstream of the Horgan and Anandakrishnan (2006) grounding line and does not contain any significant noise from hyperbolic echoes likely due to basal crevassing (Table 1). An example of the effect of basal crevassing upon $P_{\mathrm{r} 1}$ and $P_{\mathrm{r} 2}$ is observed between $\mathrm{km} 0$ and $\mathrm{km} 7$, and at $\mathrm{km} 28$ and $\mathrm{km} 36$ of transect $\mathrm{K} 4$ (Fig. $3 \mathrm{~b}$ ). For transects $\mathrm{K} 2-\mathrm{K} 4$, which have a large portion of data $(>40 \mathrm{~km})$ downstream of the point at which the ice stream is in hydrostatic equilibrium with the ocean (point ' $\mathrm{H}$ ' in Fig. 1), we only use data downstream of that point. One exception to this approach is transect K1, which did not extend beyond the regular basal crevassing downstream of the grounding line (its basal crevassing is similar to K4; Fig. 3a). For this profile, we used a portion of the transect upstream of the grounding line that is free of basal crevassing. Interestingly, this reversed approach did not produce a noticeably different result.

For transect $\mathrm{W} 1$ (Fig. 2), there is no significant change in $P_{\mathrm{r} 1}, P_{\mathrm{r} 2}$ or $P_{\mathrm{r} 2} / P_{\mathrm{r} 1}$ across most of the transect. There is also no clear trend between ice thickness and $P_{\mathrm{r} 2} / P_{\mathrm{r} 1}$, despite extending $>10 \mathrm{~km}$ downstream of the well-defined grounding line there (Horgan and Anandakrishnan, 2006). The decrease in $P_{\mathrm{r} 1}$ and $P_{\mathrm{r} 2}$ upstream of $\mathrm{km} 10$ appears to be due to destructive interference from a basal crevasse. Between $\mathrm{km} 6.5$ and $\mathrm{km} \mathrm{10,} \mathrm{where} \mathrm{the} \mathrm{receiver} \mathrm{gain} \mathrm{was} \mathrm{manually}$ lowered, $P_{\mathrm{r} 1}$ and $P_{\mathrm{r} 2}$ are $\sim 5 \mathrm{~dB}$ lower than adjacent sections of this transect. However, $P_{\mathrm{r} 2} / P_{\mathrm{r} 1}$ values along this portion of this transect remain unchanged. This receiver-gain change serendipitously provides additional confirmation that the echo observed at twice the travel time of the primary bed echo is indeed its first multiple, rather than a possible artifact of the radar system itself (Catania and others, 2006), and that $P_{\mathrm{r} 2} / P_{\mathrm{r} 1}$ is a robust quantity to use to infer attenuation.

Between km 5 and $\mathrm{km} 7$ along transect K4 (Fig. 3), $P_{\mathrm{r} 2} / P_{\mathrm{r} 1}$ does not vary smoothly and is noisier than the rest of the transect, likely due to the presence of basal crevasses and variability in ice thickness in this region. Downstream of $\mathrm{km} 40, P_{\mathrm{r} 2} / P_{\mathrm{r} 1}$ decreases with decreasing ice thickness, contrary to its predicted behavior (Equation (3)). We therefore only use $P_{\mathrm{r} 2} / P_{\mathrm{r} 1}$ values between $\mathrm{km} 13$ and $\mathrm{km} 40$ to calculate the depth-averaged attenuation rate. There, the assumption of uniform bed reflectivity is reasonable. The uncertainty in attenuation rate for this transect is negligible (Table 1), because of the higher signal-to-noise ratio of the $\mathrm{K} 4$ data.

Our depth-averaged attenuation rates (Table 1) are similar to previously reported values for this region (summarized by Jacobel and others, 2009), although uncertainties are often large where the ice-thickness range is small. Using our attenuation-rate values, we estimated along-transect values of $R_{\mathrm{ib}}$, assuming that the attenuation rate is uniform along the entire transect (Figs $2 \mathrm{~d}$ and $3 \mathrm{~d}$ ). We assumed a uniform value of $R_{\mathrm{ib}}$ across the floating portion of the transect in 
order to calculate the attenuation rate. Because this calculation essentially corrects $P_{\mathrm{r} 2} / P_{\mathrm{r} 1}$ for the spatial variation of ice thickness by correcting for the effects of geometric spreading and attenuation, it highlights other portions of each transect where the assumption of a uniform reflectivity or attenuation rate may not be valid. We tested several horizontal averaging lengths for $P_{\mathrm{r} 1}$ and $P_{\mathrm{r} 2}$, and found that attenuation-rate uncertainty generally decreased with shorter averaging lengths or no averaging, although the attenuation rates did not change significantly. We thus kept the horizontal averaging length as equal to the mean radius of the first Fresnel zone, since it is a natural length scale over which to average noisy data.

For noisier transects, such as W1, there are no clear deviations in bed reflectivity from the assumed uniform ice/ sea-water value $(-0.16 \mathrm{~dB})$. Significantly positive values of $R_{\mathrm{ib}}$ are nonphysical, but the mean $R_{\mathrm{ib}}$ along the entire transect is $1.1 \pm 0.5 \mathrm{~dB}$, and there are few values outside that range. For $\mathrm{K} 4$ between $\mathrm{km} 5$ and $\mathrm{km} 7, R_{\mathrm{ib}}$ is noisier, although its mean value between $\mathrm{km} 5$ and $\mathrm{km} 1$ is not significantly different from that at an ice/sea-water interface.

We performed the same bed-reflectivity analysis for all other transects (Figs 4 and 5) and found either no significant change in bed reflectivity across the grounding zone or, paradoxically, an increase in bed reflectivity upstream of it. In other words, the best-fit attenuation rate across the floating portion of each transect implies that bed reflectivity did not significantly decrease within or upstream of the grounding zone. We next seek to explain these observations and their implications for basal conditions there.

\section{BED-REFLECTIVITY MODELS}

We assumed that bed reflectivity across the portions of the transects over which we calculated the attenuation rate is equal to that due to a smooth ice/sea-water interface. In this section, we present reflectivity models that account for subglacial water layers of variable conductivity and thickness, in order to interpret bed reflectivity across the grounding zone.

We use a three-layer reflectivity model (Fig. 6) to calculate the total (power) reflectivity $R$ (Born and Wolf, 1999):

$$
R=20 \log _{10}\left|r_{01}+t_{01} r_{12} t_{01} \frac{\exp \left(-2 i k_{\mathrm{i}} \delta\right)}{1-r_{12} r_{10} \exp \left(-2 i k_{\mathrm{i}} \delta\right)}\right|,
$$

where $r$ and $t$ are the complex (amplitude) Fresnel reflection and transmission coefficients of each interface, respectively, and $k_{1}$ and $\delta$ are the electromagnetic propagation constant and thickness of the intermediate layer, respectively. The first subscript for $r$ and $t$ indicates which medium the ray path is traveling through upon arriving at the interface, and the second subscript indicates which medium it is incident upon. This model accounts for both multiple reflections and attenuation within the intermediate layer. A three-layer model is necessary because the thicknesses of the intermediate layers considered here are often less than their skin depth, which implies that the reflection from the bottom interface can interfere with the total reflected wave, depending on the wavelength in the layer and the layer thickness. A potential disadvantage of this model is that it assumes that the interfaces are abrupt and smooth relative to the englacial wavelength of our radar system $(85 \mathrm{~m})$.

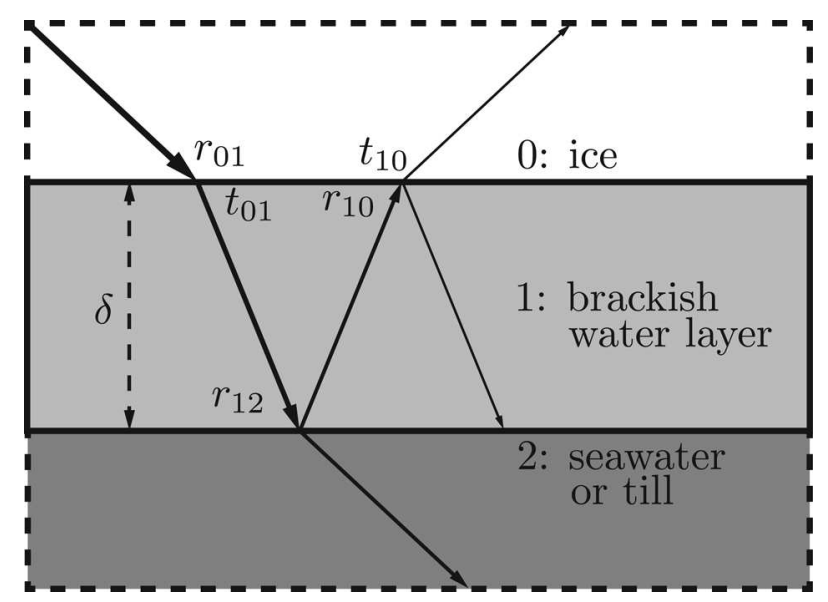

Fig. 6. Illustration of three-layer reflectivity model of ice/bed interface. Arrows represent ray paths; dashed lines represent halfspaces.

\subsection{Ice/brackish-water/sea-water}

Basal melting below the ice shelf may produce a brackish water layer of variable thickness and conductivity (proportional to its salinity; Ellison and others, 1998) just below the ice bottom that decreases $R_{\mathrm{ib}}$ for floating ice, relative to a smooth ice/sea-water interface. Transient subglacial discharge of meltwater from farther upstream (Fricker and others, 2007) or the periodic increase in sea-water influx upstream and into the grounding zone, due to tidal forcing, could also lead to the presence of a brackish water layer.

We calculate the reflectivity of this interface for a range of water-layer thicknesses and conductivities, while holding the dielectric properties of the top (ice) and bottom (sea water) half-spaces fixed (Fig. 6). Our results differ slightly from previous work (e.g. Shabtaie and others, 1987) due to the frequency, the values of the dielectric properties, and the nature of the interface considered. The water-layer thicknesses we consider $(0.01-10 \mathrm{~m})$ are often smaller than their skin depths $(36 \mathrm{~m}$ for melted meteoric ice; $0.2 \mathrm{~m}$ for sea water). The background conductivity of melted meteoric ice from inland Antarctica is $\sim 10^{-4} \mathrm{~S} \mathrm{~m}^{-1}$ (e.g. Röthlisberger and others, 2000). This value is conservatively the minimum conductivity of this brackish water layer at $2 \mathrm{MHz}$, and the conductivity of sea water at a frequency of $3 \mathrm{GHz}$ and a temperature of $-2^{\circ} \mathrm{C}$ is its maximum value $\left(2.7 \mathrm{~S} \mathrm{~m}^{-1}\right.$; Ellison and others, 1998).

If the brackish water layer has a conductivity exceeding $\sim 10^{-1} \mathrm{~S} \mathrm{~m}^{-1}$ and/or a thickness less than $1 \mathrm{~m}$ (Fig. 7a), the total reflectivity is dominated by the top reflection $\left(r_{01}\right.$ in Equation (6)). That reflection is itself dominated by the conductivity contrast between the ice and the water layer. For less conductive but thicker layers, destructive interference can occur between the reflected waves from the top and bottom interfaces of the layer. This interference is frequency-dependent. For our radar's center frequency $(2 \mathrm{MHz})$, it causes a reflectivity decrease greater than $5 \mathrm{~dB}$ at layer thicknesses of $\sim 5 \mathrm{~m}$ and relatively low layer conductivities $\left(<10^{-2} \mathrm{~S} \mathrm{~m}^{-1}\right)$.

The true conductivity/salinity and thickness of the putative brackish water layer below the ice bottom depends on the local basal mass balance, the sub-shelf ocean circulation and bathymetry, and transient water fluxes. The modeled mean basal melt rate for the Ross Ice Shelf in this region is only 
a: Ice-layer/sea water

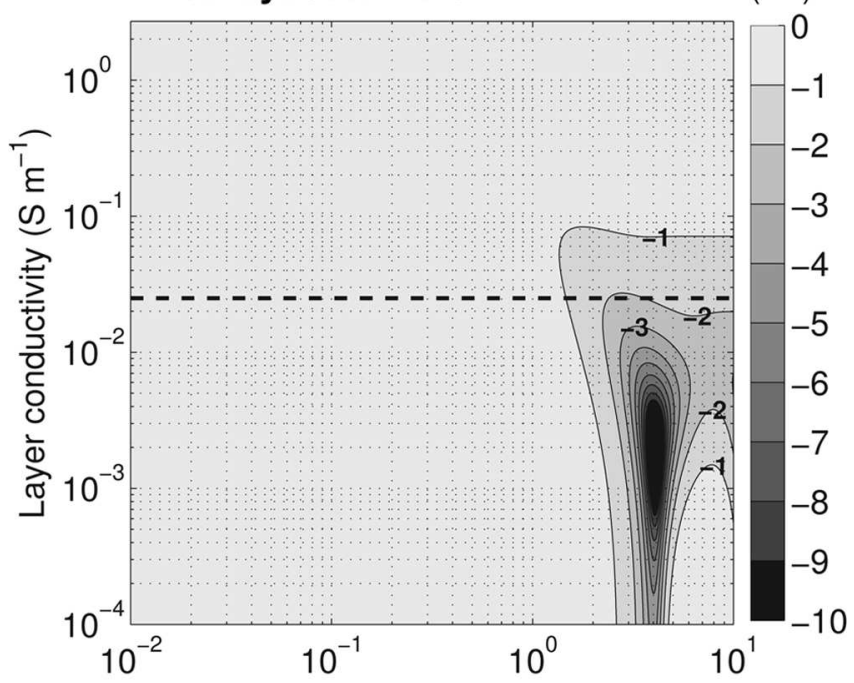

b: Ice-layer/till

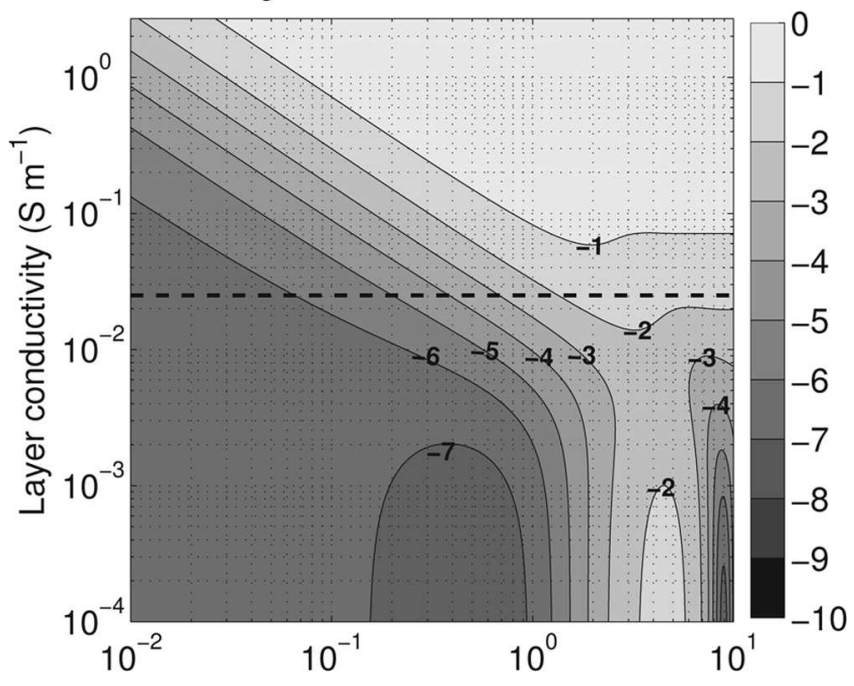

c: Difference (b-a)

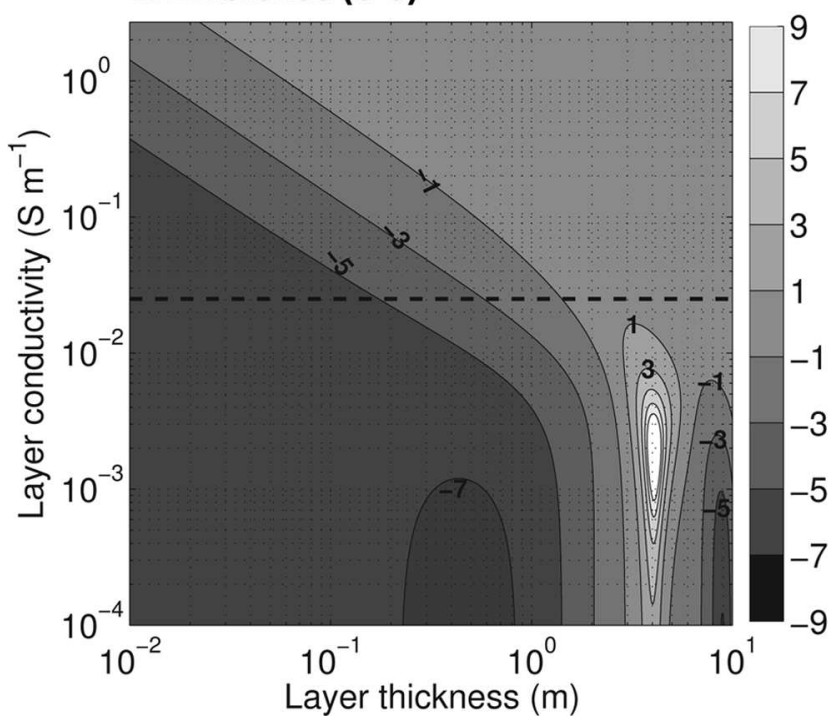

Fig. 7. (a) Modeled reflectivity of an ice/sea-water interface with a layer of brackish water between, as a function of that layer's thickness and conductivity. Horizontal black dashed line is the water conductivity reported by Engelhardt and others (1990a) underneath Whillans Ice Stream. Contour interval $1 \mathrm{~dB}$ (both labels and color scale). (b) Same as (a) but for an ice/till interface. (c) Reflectivity difference between the ice/till and ice/sea-water interfaces. Contour interval $2 \mathrm{~dB}$. $\sim 0.4 \mathrm{~m} \mathrm{a}^{-1}$ (Holland and others, 2003). Although basal melt rates near the grounding lines of some Antarctic glaciers may reach $40 \mathrm{~m} \mathrm{a}^{-1}$ (Rignot and Jacobs, 2002), Catania and others (2010) found limited evidence of basal melting across the nearby Siple Dome grounding line, and Matsuoka and others (2009) suggested an order-of-magnitude decrease in basal melt rates from the northern to the southern relict grounding lines for Kamb Ice Stream. A brackish layer thicker than $1 \mathrm{~m}$ seems unlikely to persist underneath the ice shelf, unmixed with sea water. Any significant brackish layer will probably have a conductivity greater than $10^{-1} \mathrm{~S} \mathrm{~m}^{-1}$ (an intermediate value between sea water and that reported by Engelhardt and others, 1990a). We conclude that the reflectivity of an ice/ brackish-water-layer/sea-water interface at $2 \mathrm{MHz}$ is effectively the same as that of the ice/sea-water interface (to within $\sim 1 \mathrm{~dB}$ ) for any reasonable variation in the properties of the intermediate layer.

\subsection{Ice/brackish-water/till}

On grounded ice, which is most likely underlain by a layer of deformable till in our study area, the nature of the ice bottom is inevitably more complex. The till may be watersaturated, water channels may be present, and the till may be patchy or of varying lithology. The reflectivity of an ice/till interface depends upon the degree of water saturation of the till and the dielectric properties of both the till and the pore water it contains. A reasonable upper limit for the Fresnel reflectivity of an ice/till interface at $2 \mathrm{MHz}$ is $-6.5 \mathrm{~dB}$, assuming that the till is unfrozen and contains $40 \%$ groundwater $\left(\varepsilon_{\text {till }}=18-14.8 i\right.$; Anandakrishnan and others, 2007). That calculation also assumes that the till is thick relative to its skin depth $(\sim 10 \mathrm{~m})$. Although the till wedge observed by Anandakrishnan and others (2007) along W1 appears to pinch out upstream (Fig. 2a), sediment thicknesses of several hundred meters are widespread underneath large portions of the Ross embayment, West Antarctica (Robertson and Bentley, 1990; Anandakrishnan and Winberry, 2004). We assume that a similar layer of deformable till is present underneath Kamb Ice Stream.

Engelhardt and others (1990a) found that the conductivity of subglacial water from underneath Whillans Ice Stream was $\sim 0.025 \mathrm{~S} \mathrm{~m}^{-1}$, which is an intermediate value given the above range $\left(10^{-4}-2.7 \mathrm{~S} \mathrm{~m}^{-1}\right)$, and equivalent to $0.9 \%$ of the conductivity of sea water. Skidmore and others (2010) found that the $\mathrm{Na}^{+}$and $\mathrm{Cl}^{-}$concentrations of pore water in till from beneath Kamb and Bindschadler Ice Streams were $4-7 \%$ and $0.2-0.4 \%$ of their concentrations in sea water, respectively. The conductivity of sea water is linearly proportional to its salinity (Ellison and others, 1998), so the pore-water concentrations reported by Skidmore and others (2010) are roughly consistent with the subglacial water conductivity reported by Engelhardt and others (1990a). The conductivity of a putative subglacial water layer, or till pore water, is unlikely to be uniform across the entire Ross ice-stream system or even an individual ice stream. However, the similarity of the observed properties of subglacial water between widely separated boreholes suggests that the intermediate conductivity value reported by Engelhardt and others (1990a) is the most appropriate for this reflectivity model.

Figure $7 \mathrm{~b}$ shows the total reflectivity of the ice/brackishwater/till model. To produce a total reflectivity close to that of an ice/sea-water interface $(-0.16 \mathrm{~dB})$, the brackish layer must both have a high conductivity $\left(>10^{-1} \mathrm{~S} \mathrm{~m}^{-1}\right)$ and be at 
least thicker than $0.1 \mathrm{~m}$. Thinner brackish layers generally produce smaller reflectivities, and destructive interference can occur when the layer conductivity is low $\left(<10^{-2} \mathrm{~S} \mathrm{~m}^{-1}\right)$ and its thickness is large $(\sim 7-10 \mathrm{~m})$.

The difference between the ice/brackish-water/sea-water and the ice/brackish-water/till models is shown in Figure 7c. Where this difference is small is indicative of the range of layer properties that could explain the observed lack of change in bed reflectivity, which occurs when both layer conductivities and thicknesses are large.

\subsection{Roughness}

Relative to a specular reflection from a smooth interface, a rougher ice bottom will cause increased diffuse scattering and decreased coherent backscattering (Peters and others, 2005). For all reflectivity models, we assume that reflection from the ice bottom is specular and that the interface is uniformly smooth. Here we evaluate this assumption by estimating the reflectivity decrease at nadir due to roughness, $\rho$, following Peters and others (2005):

$$
\rho=\exp \left(-g^{2}\right) I_{0}^{2}\left(\frac{g^{2}}{2}\right),
$$

where $g=4 \pi \nu / \lambda$ and $I_{0}$ is the zero-order modified Bessel function. $\nu$ is the root-mean-square (RMS) deviation of bed elevation (Shepard and others, 2001) and $\lambda$ is the radar wavelength in ice, so $g$ can be thought of as the wavelengthnormalized bed roughness.

We divided each transect into two sections: one upstream of the Horgan and Anandakrishnan (2006) grounding line and one downstream of it. The value of $\rho$ was less than $-0.5 \mathrm{~dB}$ for only two transect sections, both of which were downstream of the grounding line and had regular basal crevassing. This small possible effect is due to the large englacial radar wavelength $(85 \mathrm{~m})$. It suggests that changes in bed roughness do not significantly affect the observed bed-echo intensities.

\section{DISCUSSION}

\subsection{Basal conditions across the grounding zone}

Horgan and Anandakrishnan (2006) mapped the Siple Coast grounding line via characteristic surface-elevation 'ramps' from satellite laser altimetry. They validated this method near W1 and W2 using the spatial variation of tidally driven surface-elevation changes, measured by GPS. In this region, their grounding line is within $2 \mathrm{~km}$ of the landward limit of flexure determined by Brunt and others (2010). However, we did not detect any significant change in bed reflectivity across the grounding zone of the W1 and W2 transects (Figs $2 \mathrm{~d}$ and $4 \mathrm{a}$ and $\mathrm{b}$ ). This observation suggests that $2 \mathrm{MHz}$ radar is insensitive to whatever changes may occur in either the dielectric properties or roughness of the interface there. Similarly, for the Kamb Ice Stream transects (Figs 3 and 5), we did not detect a clear change in bed reflectivity across the grounding line.

Overestimation of the magnitude of the attenuation rate leads to overestimation of the bed reflectivity (and vice versa). The englacial attenuation rate increases exponentially with increasing temperature (MacGregor and others, 2007). Basal melting is predicted across most of the Ross Ice Shelf downstream of its grounding zone (Holland and others, 2003), which lowers the depth-averaged temperature there relative to upstream grounded ice by removing warm basal ice (Holland and others, 2003). This scenario implies that our attenuation rates estimated from the floating-ice section of each transect may underestimate the attenuation rate on grounded ice. This underestimation is particularly likely for the southern Kamb Ice Stream transects (K5-K9), where basal freezing is predicted for the grounded ice (Joughin and others, 2004), which further warm the ice relative to downstream floating ice. Despite these thermal considerations, bed reflectivity is roughly uniform (or even non-physically positive) within and upstream of the grounding zone for all transects studied.

Ross Ice Shelf Geophysical and Glaciological Survey (RIGGS) seismic data show that the thickness of the water cavity is non-negligible both within and downstream of the grounding zone, and zero upstream of the grounding zone, except for the Whillans Ice Plain (Fig. 1; Robertson and Bentley, 1990). For example, the water-cavity thickness is $30 \mathrm{~m}$ downstream of $\mathrm{W} 1,41 \mathrm{~m}$ within the grounding zone near $\mathrm{K} 1$, yet zero just upstream of $\mathrm{K} 4$. The given uncertainties for these values are $\pm 5-10 \mathrm{~m}$, depending on the details of the method used. Though sparse, these RIGGS data are consistent with a conventional view of the grounding zone, i.e. Kamb Ice Stream is well grounded upstream of its grounding zone, and its ice bottom quickly separates from the sea-floor soon after the ice goes afloat downstream, forming at least a multi-meter water cavity. We note that, given uncertainties present in these earlier data, they do not preclude the presence of a thin water layer upstream of the grounding zone, as has been inferred by several subsequent radar studies (e.g. Bentley and others, 1998) and direct investigations (e.g. Engelhardt and others, 1990b).

A synthesis of these observations suggests two possible scenarios: (1) we overestimated the fixed bed reflectivity used to calculate the attenuation rate across the floating ice, thus overestimating the attenuation rate and bed reflectivity farther upstream; or (2) our estimate of the fixed bed reflectivity on floating ice is accurate, and bed reflectivity is indeed uniform across the grounding zones crossed by our transects.

The first scenario suggests that bed reflectivity over the floating ice is at least several decibels lower than that of an ice/sea-water interface. We have already ruled out spatial variation in bed roughness as a possible cause of such a decrease. Our reflectivity models suggest that, for an ice/ brackish-water/sea-water interface, the necessary decrease would occur only when the brackish layer had a narrow thickness range $(\sim 5 \mathrm{~m})$ and a conductivity lower than that observed underneath Whillans Ice Stream. If the floating ice over which we fitted the attenuation rate is underlain by a till half-space, rather than sea water, small layer thicknesses $(<1 \mathrm{~m})$ and high conductivities would be necessary to reproduce the observed decrease in reflectivity. These results imply that even several tens of kilometers downstream of the grounding line, as for $\mathrm{K} 2-\mathrm{K} 4$, the water layer separating the ice shelf from the sea-floor has to be surprisingly thin. Although we lack constraints on the water thickness along most of the transects in this study, the RIGGS data show that this scenario is unlikely, especially for the longer transects (K2-K4).

Rather than appeal to the above scenario along all our transects, we consider the second scenario, which suggests that bed reflectivity did not change significantly upstream and across the grounding zone. The difference between the 
two reflectivity models must be small $(<2 \mathrm{~dB})$ to explain the observed lack of bed-reflectivity change, which occurs when the layer conductivity is $>\sim 10^{-1} \mathrm{~S} \mathrm{~m}^{-1}$ and its thickness is $>\sim 0.2 \mathrm{~m}$ (Fig. 7c). Layer conductivities that high upstream of the grounding zone may be possible if subglacial meltwater originating from farther upstream has had more time to leach impurities from till, if sea water infiltrated upstream of the grounding line, or if the subglacial meltwater system is not sufficiently well connected to flush out impurities (Catania and others, 2003). Engelhardt and others (1990b) found an active subglacial water system farther upstream on Whillans Ice Stream, so sufficiently thick water layers may be possible. However, the infiltration of sea water upstream is unlikely for grounding zones that have a large surfaceelevation ramp, such as Kamb Ice Stream, which produces a subglacial hydropotential 'barrier' to subglacial water flow upstream of the grounding zone.

The unusually weak coupling of the Whillans Ice Plain to its bed (Winberry and others, 2009) suggests that, in addition to low driving stresses, its bed is well lubricated. Kamb Ice Stream also has a weak bed (Joughin and others, 2004), although it is not as strongly tidally coupled as the Whillans Ice Plain (Bindschadler and others, 2003). In the downstream region of Kamb Ice Stream, ice-flow speeds are low and any subglacial water is likely freezing to its bed. Despite this pattern, direct observations found that its basal sediments are still lubricated (Vogel and others, 2005) and several radar surveys have also found high bed reflectivity across its stagnated downstream trunk (Bentley and others, 1998; Catania and others, 2003; Peters and others, 2005; Jacobel and others, 2009). Those observations support the hypothesis that a water-lubricated bed is a necessary but insufficient condition for fast ice flow. Our results are also consistent with that hypothesis, in that the bed is clearly wet underneath grounded ice in these regions, although here we provide additional constraints on the nature of that interface.

Jacobel and others (1994) observed a $\sim 3 \mathrm{~dB}$ change in bed-echo intensity within a $\sim 2 \mathrm{~km}$ span across the grounding line of MacAyeal Ice Stream. The putative bedreflectivity change there differs markedly from our observations across the grounding zones of Whillans and Kamb Ice Streams. Assuming the dielectric properties of the till in their study area are similar to those we used in reflectivity models for Whillans and Kamb Ice Streams, their $3 \mathrm{~dB}$ increase in bed-echo intensity as they cross the grounding line suggests lower water-layer conductivity and thickness upstream of the grounding zone there. This difference suggests that there is spatial variation in the nature of the Ross Ice Shelf's grounding zone, i.e. it is abrupt in some regions and gradual in others.

\subsection{Transition from basal melting to accretion?}

A portion of the $\mathrm{K} 4$ transect shows an unusual pattern in the relationship between $P_{\mathrm{r} 2} / P_{\mathrm{r} 1}$ and ice thickness. Downstream of $\mathrm{km} 40, P_{\mathrm{r} 2} / P_{\mathrm{r} 1}$ begins to decrease steadily, although ice thickness continues to decrease smoothly (Fig. 3c). This pattern is contrary to the predicted inverse relationship between $P_{\mathrm{r} 2} / P_{\mathrm{r} 1}$ and ice thickness (Equation (3)). It suggests either a decrease in the bed reflectivity or an increase in the attenuation rate there. We rule out any change in the firn/air reflectivity because the echo intensity of the primary bed echo, which is independent of the firn/air reflectivity (Equation (1)), also begins decreasing at $\mathrm{km} \mathrm{40.} \mathrm{Based} \mathrm{on}$ flow stripes visible in the Moderate Resolution Imaging
Spectroradiometer (MODIS) Mosaic of Antarctica (MOA; Fig. 1), K4 is historically flow-parallel along its entire length, and the continuity of those flow stripes suggests that the ice shelf does not become lightly grounded there.

If we attribute this change in the trend of $P_{\mathrm{r} 2} / P_{\mathrm{r} 1}$ entirely to bed reflectivity, it requires a cumulative decrease of $\sim 4 \mathrm{~dB}$ by the end of the transect. Such a decrease could be due to either increasing interface roughness or a less distinct, slushy interface, such as an accreting ice-shelf bottom (Engelhardt and Determann, 1987). However, the RMS deviation of bed elevation does not increase, so we do not suspect a significant change in the ice-bottom roughness. The change in trend could also be explained separately by a cumulative increase in the depth-averaged attenuation rate of $\sim 2.5 \mathrm{~dB}$ $\mathrm{km}^{-1}$ by the end of the transect, $10 \mathrm{~km}$ downstream of the onset of this change in trend. Following MacGregor and others (2007), simple one-dimensional attenuation-rate modeling (assuming uniform chemistry) shows that such an attenuation-rate increase is equivalent to an increase in the mean ice-column value of either temperature $(+1.8 \mathrm{~K})$, acidity $\left(+0.7 \mu \mathrm{mol} \mathrm{L}^{-1}\right)$, salinity $\left(+5 \mu \mathrm{mol} \mathrm{L}^{-1}\right)$ or a combination of smaller changes in these properties. However, such changes are large compared to the expected horizontal spatial variation of depth-averaged temperature or chemistry across $15 \mathrm{~km}$ along a flowline (MacGregor, 2008).

Although we cannot unambiguously distinguish the nature of the decrease in the primary bed-echo intensity near the end of $\mathrm{K} 4$, the onset of basal ice accretion is the most likely cause. Ice-penetrating radar is doubly sensitive to the onset of basal accretion, due to the probable decrease in bed reflectivity, and the increase in attenuation rate associated with warmer marine ice. Bentley and others (1998) also proposed basal accretion as a possible cause of the leftskewed range of bed reflectivities observed using airborne radar over the Ross Ice Shelf (see also Neal, 1979). Neither an increase in ice-bottom roughness nor a persistent brackish water layer can reasonably explain the reflectivity decrease along $\mathrm{K} 4$ beginning $40 \mathrm{~km}$ past the grounding line.

Ice-ocean modeling predicts basal melting near the grounding line and slower basal accretion confined to the central cavity of the Ross Ice Shelf, $>200 \mathrm{~km}$ downstream of the Kamb Ice Stream grounding line (Holland and others, 2003). Our K4 transect suggests that the onset of basal accretion is much closer to the grounding line than previously predicted. Curiously, transects $\mathrm{K} 2$ and $\mathrm{K} 3$ do not show the same change in $P_{\mathrm{r} 2} / P_{\mathrm{r} 1}$ as $\mathrm{K} 4$ (Fig. 5), yet they are only 10 and $5 \mathrm{~km}$ farther north, respectively. Catania and others (2010) found evidence in radar stratigraphy that the pattern of sub-ice-shelf melting near the grounding line in this region can be more highly focused than previously predicted. Combining these results, we suggest that existing basal mass-balance models do not yet adequately resolve the pattern of basal melting and accretion near the grounding line, possibly causing modeled basal melting to skew farther downstream. Additional ice-thickness and subice-shelf bathymetry data will permit ice-shelf-ocean modeling at finer resolution and help resolve this apparent difference, along with the finer spatial variability of basal ice accretion underneath the Ross Ice Shelf.

\section{CONCLUSIONS}

We have presented a method for inferring depth-averaged englacial radar-attenuation rates from multiple echoes, and 
have shown that changes in $P_{\mathrm{r} 2} / P_{\mathrm{r} 1}$ can help detect and interpret changes in bed reflectivity. Increasingly sensitive and higher-power radars will allow the use of this technique in thicker, colder and/or grounded ice. Indeed, multiple bed echoes have also recently been observed in radar data collected over grounded ice in East Antarctica (Jacobel and others, 2010; personal communication from D. Braaten, 2009). When designing an ice-penetrating radar survey, a trade-off must typically be made between the length of the recording time window and the number of stacks used to average out incoherent noise, i.e. a longer time window necessitates a smaller stack (and vice versa). Our results emphasize the value of recording traces for a sufficiently long time window to detect and potentially make use of multiple echoes.

From the perspective of radar bed reflectivity, we find that the grounding zone is often ambiguous. By measuring attenuation rates near the grounding line, we have shown that bed reflectivity does not decrease significantly across the transition zone from grounded to floating ice. This observation supports existing arguments that a zone of weak ice-bed coupling at least several kilometers wide exists for Whillans Ice Stream, and that the bed of Kamb Ice Stream is still wet upstream of its grounding line. From straightforward reflectivity modeling, we suggest that a persistent conductive water layer upstream of the grounding zone best explains the observed lack of change in bed reflectivity. We also find the onset of basal ice accretion can be much closer to the Kamb Ice Stream grounding line than existing basal massbalance models suggest. Additional direct (e.g. borehole drilling) or indirect (common-midpoint radar and/or seismic survey) investigations could resolve the remaining ambiguity concerning the nature of the bed across the Ross Ice Shelf grounding zone, and any other ice shelves whose basal transition is especially gradual.

\section{ACKNOWLEDGEMENTS}

This work was supported by the US National Science Foundation (ANT 0538120 to Catania, ANT 0226535 to Anandakrishnan and ANT 0538674 to Winebrenner), the Center for Remote Sensing of Ice Sheets (NSF 0424589) and the Gary Comer Science and Education Foundation. We thank numerous field assistants, the US Antarctic Program for logistical support, K.M. Brunt for providing her picks of the Ross Ice Shelf grounding zone, I.R. Joughin, R.B. Alley, H.J. Horgan, R.T. Walker and R.W. Jacobel for valuable discussions, four anonymous referees of previous versions of the paper for constructive reviews, and two anonymous referees for constructive reviews.

\section{REFERENCES}

Anandakrishnan, S. and J.P. Winberry. 2004. Antarctic subglacial sedimentary layer thickness from receiver function analysis. Global Planet. Change, 42(1-4), 167-176.

Anandakrishnan, S., G.A. Catania, R.B. Alley and H.J. Horgan. 2007. Discovery of till deposition at the grounding line of Whillans Ice Stream. Science, 315(5820), 1835-1838.

Bentley, C.R., N. Lord and C. Liu. 1998. Radar reflections reveal a wet bed beneath stagnant Ice Stream $C$ and a frozen bed beneath ridge BC, West Antarctica. J. Glaciol., 44(146), 149-156.
Bindschadler, R.A., M.A. King, R.B. Alley, S. Anandakrishnan and L. Padman. 2003. Tidally controlled stick-slip discharge of a West Antarctic ice stream. Science, 301(5636), 1087-1089.

Bogorodsky, V.V., C.R. Bentley and P.E. Gudmandsen. 1985. Radioglaciology. Dordrecht, etc., D. Reidel.

Born, M. and E. Wolf. 1999. Principles of optics. Seventh edition. Cambridge, Cambridge University Press.

Brunt, K.M., H.A. Fricker, L. Padman, T.A. Scambos and S. O'Neel. 2010. Mapping the grounding zone of Ross Ice Shelf, Antarctica, using ICESat laser altimetry. Ann. Glaciol., 51(55), 71-79.

Catania, G.A., H.B. Conway, A.M. Gades, C.F. Raymond and H. Engelhardt. 2003. Bed reflectivity beneath inactive ice streams in West Antarctica. Ann. Glaciol., 36, 287-291.

Catania, G.A., T.A. Scambos, H. Conway and C.F. Raymond. 2006. Sequential stagnation of Kamb Ice Stream, West Antarctica. Geophys. Res. Lett., 33(14), L14502. (10.1029/2006GL026430.)

Catania, G.A., T.A. Neumann and S.F. Price. 2008. Characterizing englacial drainage in the ablation zone of the Greenland ice sheet. J. Glaciol., 54(187), 567-578.

Catania, G.A., C.L. Hulbe and H.B. Conway. 2010. Grounding-line basal melt rates determined using radar-derived internal stratigraphy. J. Glaciol., 56(197), 545-554.

Corr, H.F.J., C.S.M. Doake, A. Jenkins and D.G. Vaughan. 2001. Investigations of an 'ice plain' in the mouth of Pine Island Glacier, Antarctica. J. Glaciol., 47(156), 51-57.

Ellison, W. and 6 others. 1998. New permittivity measurements of seawater. Radio Sci., 33(3), 639-648.

Engelhardt, H. and J. Determann. 1987. Borehole evidence for a thick layer of basal ice in the central Ronne Ice Shelf. Nature, 327(6120), 318-319.

Engelhardt, H., N. Humphrey and B. Kamb. 1990a. Borehole geophysical observations on Ice Stream B, Antarctica. Antarct. J. US, 25(5), 80-82.

Engelhardt, H., N. Humphrey, B. Kamb and M. Fahnestock. $1990 \mathrm{~b}$. Physical conditions at the base of a fast moving Antarctic ice stream. Science, 248(4951), 57-59.

Fricker, H.A., T. Scambos, R. Bindschadler and L. Padman. 2007. An active subglacial water system in West Antarctica mapped from space. Science, 315(5818), 1544-1548.

Gades, A.M., C.F. Raymond, H. Conway and R.W. Jacobel. 2000. Bed properties of Siple Dome and adjacent ice streams, West Antarctica, inferred from radio-echo sounding measurements. J. Glaciol., 46(152), 88-94.

Gogineni, S., T. Chuah, C. Allen, K. Jezek and R.K. Moore. 1998. An improved coherent radar depth sounder. J. Glaciol., 44(148), 659-669.

Holland, C.W. and S. Anandakrishnan. 2009. Subglacial seismic reflection strategies when source amplitude and medium attenuation are poorly known. J. Glaciol., 55(193), 931-937.

Holland, D.M., S.S. Jacobs and A. Jenkins. 2003. Modelling the ocean circulation beneath the Ross Ice Shelf. Antarct. Sci., 15(1), 13-23.

Horgan, H.J. and S. Anandakrishnan. 2006. Static grounding lines and dynamic ice streams: evidence from the Siple Coast, West Antarctica. Geophys. Res. Lett., 33(18), L18502. (10.1029/ 2006GL027091.)

Jacobel, R.W., A.E. Robinson and R.A. Bindschadler. 1994. Studies of the grounding-line location on Ice Streams $D$ and $E$, Antarctica. Ann. Glaciol., 20, 39-42.

Jacobel, R.W., B.C. Welch, D. Osterhouse, R. Pettersson and J.A. MacGregor. 2009. Spatial variation of radar-derived basal conditions on Kamb Ice Stream, West Antarctica. Ann. Glaciol., 50(51), 10-16.

Jacobel, R.W., K.E. Lapo, J.R. Stamp, B.W. Youngblood, B.C. Welch and J.L. Bamber. 2010. A comparison of basal reflectivity and ice velocity in East Antarctica. Cryosphere, 4(4), 447-452.

Joughin, I., S. Tulaczyk, D. MacAyeal and H. Engelhardt. 2004. Melting and freezing beneath the Ross ice streams, Antarctica. J. Glaciol., 50(168), 96-108. 
Langway, C.C., Jr. 1975. Antarctic ice core studies. Antarct. J. US, 10(4), 152-153.

Looyenga, H. 1965. Dielectric constant of heterogeneous mixtures. Physica, 31(3), 401-406.

MacGregor, J. 2008. Development and applications of a radarattenuation model for polar ice sheets. (PhD thesis, University of Washington.)

MacGregor, J.A., D.P. Winebrenner, H. Conway, K. Matsuoka, P.A. Mayewski and G.D. Clow. 2007. Modeling englacial radar attenuation at Siple Dome, West Antarctica, using ice chemistry and temperature data. J. Geophys. Res., 112(F3), F03008. (10.1029/2006JF000717.)

Matsuoka, K., A. Gades, H. Conway, G. Catania and C. Raymond. 2009. Radar signatures beneath a surface topographic lineation near the outlet of Kamb Ice Stream and Engelhardt Ice Ridge, West Antarctica. Ann. Glaciol., 50(51), 98-104.

Matsuoka, K., D. Morse and C.F. Raymond. 2010. Estimating englacial radar attenuation using depth profiles of the returned power, central West Antarctica. J. Geophys. Res., 115(F2), F02012. (10.1029/2009JF001496.)

Neal, C.S. 1979. The dynamics of the Ross Ice Shelf revealed by radio echo-sounding. J. Glaciol., 24(90), 295-307.

Peters, L.E., S. Anandakrishnan, C.W. Holland, H. Horgan, D.D. Blankenship and D.E. Voigt. 2008. Seismic detection of a subglacial lake near the South Pole, Antarctica. Geophys. Res. Lett., 35(23), L23501. (10.1029/2008GL035704.)

Peters, M.E., D.D. Blankenship and D.L. Morse. 2005. Analysis techniques for coherent airborne radar sounding: application to West Antarctic ice streams. J. Geophys. Res., 110(B6), B06303. (10.1029/2004JB003222.)

Peters, M.E., D.D. Blankenship, D.E. Smith, J.W. Holt and S.D. Kempf. 2007. The distribution and classification of bottom crevasses from radar sounding of a large tabular iceberg. IEEE Geosci. Remote Sens. Lett., 4(1), 142-146.

Rignot, E. and S.S. Jacobs. 2002. Rapid bottom melting widespread near Antarctic ice sheet grounding lines. Science, 296(5575), 2020-2023.

Robertson, J.D. and C.R. Bentley. 1990. Seismic studies on the grid western half of the Ross Ice Shelf: RIGGS I and RIGGS II. In Bentley, C.R. and D.E. Hayes, eds. The Ross Ice Shelf: glaciology and geophysics. Washington, DC, American Geophysical Union, 55-86. (Antarctic Research Series 42.)

Roethlisberger, H. 1972. Seismic exploration in cold regions. CRREL Monogr. II-A2a.

Röthlisberger, R. and 6 others. 2000. Technique for continuous high-resolution analysis of trace substances in firn and ice cores. Environ. Sci. Technol., 34(2), 338-342.
Scambos, T.A., T.M. Haran, M.A. Fahnestock, T.H. Painter and J. Bohlander. 2007. MODIS-based Mosaic of Antarctica (MOA) data sets: continent-wide surface morphology and snow grain size. Remote Sens. Environ., 111(2-3), 242-257.

Schoof, C. 2007. Ice sheet grounding line dynamics: steady states, stability, and hysteresis. J. Geophys. Res., 112(F3), F03S28. (10.1029/2006JF000664.)

Shabtaie, S. and C.R. Bentley. 1982. Tabular icebergs: implications from geophysical studies of ice shelves. J. Glaciol., 28(100), 413-430.

Shabtaie, S., I.M. Whillans and C.R. Bentley. 1987. The morphology of Ice Streams A, B, and C, West Antarctica, and their environs. J. Geophys. Res., 92(B9), 8865-8883.

Shepard, M.K., B.A. Campbell, M.H. Bulmer, T.G. Farr, L.R. Gaddis and J.J. Plaut. 2001. The roughness of natural terrain: a planetary and remote sensing perspective. J. Geophys. Res., 106(E12), $32,777-32,796$.

Skidmore, M., M. Tranter, S. Tulaczyk and B. Lanoil. 2010. Hydrochemistry of ice stream beds - evaporitic or microbial effects? Hydrol. Process., 24(4), 517-523.

Smith, A.M. 1997. Variations in basal conditions on Rutford Ice Stream, West Antarctica. J. Glaciol., 43(144), 251-261.

Stevens, C.W., B.J. Moorman, S.M. Solomon and C.H. Hugenholtz. 2009. Mapping subsurface conditions within the near-shore zone of an Arctic delta using ground penetrating radar. Cold Reg. Sci. Technol., 56(1), 30-38.

Sylvester, J., D. Winebrenner and F. Gylys-Colwell. 1996. Layer stripping for the Helmholtz equation. SIAM J. Appl. Math., 56(3), 736-754.

Uratsuka, S., F. Nishio and S. Mae. 1996. Internal and basal ice changes near grounding line derived from radio-echo sounding. J. Glaciol., 42(140), 103-109.

Vogel, S.W. and 7 others. 2005. Subglacial conditions during and after stoppage of an Antarctic Ice Stream: is reactivation imminent? Geophys. Res. Lett., 32(14), L14502. (10.1029/ 2005GL022563.)

Winberry, J.P., S. Anandakrishnan, R.B. Alley, R.A. Bindschadler and M.A. King. 2009. Basal mechanics of ice streams: insights from the stick-slip motion of Whillans Ice Stream, West Antarctica. J. Geophys. Res., 114(F1), F01016. (10.1029/2008JF001035.)

Winebrenner, D.P. 1991. Acoustic backscattering from sea ice at $10-100 \mathrm{kHz}$. Seattle, WA, University of Washington. Applied Physics Laboratory. (Tech. Rep. 9017.)

Winebrenner, D.P., B.E. Smith, G.A. Catania, H.B. Conway and C.F. Raymond. 2003. Radio-frequency attenuation beneath Siple Dome, West Antarctica, from wide-angle and profiling radar observations. Ann. Glaciol., 37, 226-232. 